Figure 1. Adjusted odds ratio of achieving MCID CDAl or modified ACR20/50/70 at 6 months after initiation of abatacept by line of therapy (primary cohort)

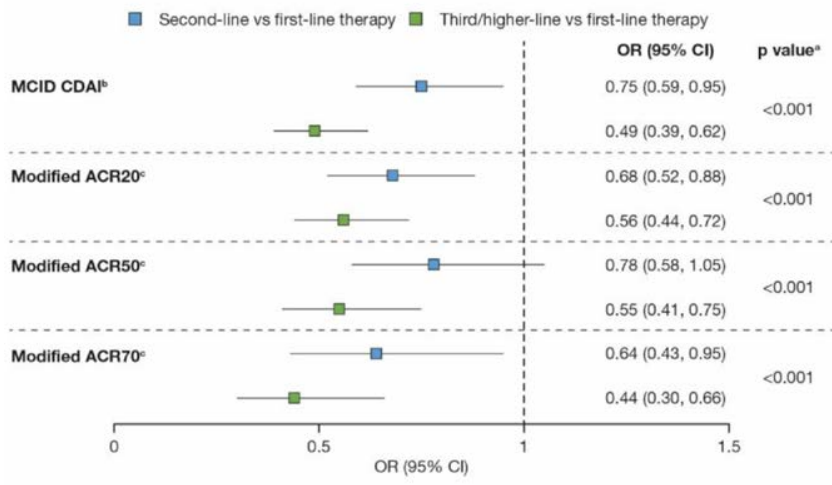

Estimated by multiple logistic regression analysis adjusted for age, sex, disease duration, work status, SC nodules, history of hypertension and depression, BL CDAI, BL, patient-reported pain and BL fatigue line of therapy): v values reflect overall difference across lines of therapy.

OW (CDAl score 510$)$; of 6 if BL disease activity was moderate (CDAl score $>10$ and 522 ); and of 11 if BL disease activity was high (CDAl score >22).

Modified ACR criteria is based on 2 out of 4 measures (not using ESR or CRP)

Modified ACR $20 / 50 / 70=20 / 50 / 70 \%$ improvement in modified $A C R$ criteria; $M C I D=$ minimal clinically importan difference; $\mathrm{OR}=$ odds ratio.

Acknowledgements: Professional medical writing and editorial assistance was provided by Claire Line, PhD, at Caudex and was funded by Bristol Myers Squibb. The poster was a collaborative effort between Corrona and Bristol Myers Squibb, with financial support provided by Bristol Myers Squibb. This study was sponsored by Corrona, LLC. Corrona is supported through contracted subscriptions with multiple pharmaceutical companies.

Disclosure of Interests: Leslie Harrold Consultant of: AbbVie, Bristol Myers Squibb, Genentech/Roche, Grant/research support from: Pfizer, Keith Wittstock Employee of: Bristol Myers Squibb, Sheila Kelly Shareholder of: Bristol Myers Squibb, Employee of: Bristol Myers Squibb, Sang Hee Park Employee of: Bristol Myers Squibb, Xue Han Employee of: Bristol Myers Squibb, Ying Shan: None declared, Carla Roberts-Toler: None declared, Nicole Middaugh: None declared, Vadim Khaychuk Shareholder of: Bristol Myers Squibb, Employee of: Bristol Myers Squibb

DOI: 10.1136/annrheumdis-2021-eular.701

\section{AB0203 $\quad$ EFFECT OF DOSE ESCALATION OF SUBCUTANEOUS TOCILIZUMAB ON DISEASE ACTIVITY IN PATIENTS WITH RHEUMATOID ARTHRITIS IN A RANDOMIZED CONTROLLED TRIAL}

N. Singer ${ }^{1}$, S. Mohan ${ }^{2}$, J. Han $^{3}$, M. Edwardes ${ }^{4}$, M. Michalska ${ }^{2} .{ }^{1}$ Case Western Reserve University and The MetroHealth System, Rheumatology, Cleveland, United States of America; ${ }^{2}$ Genentech, Inc., Immunology, South San Francisco, United States of America; ${ }^{3}$ Genentech, Inc., Biometrics, South San Francisco, United States of America; ${ }^{4}$ Everest Clinical Research, Statistical Sciences, Markham, Canada

Background: In patients with RA, subcutaneous tocilizumab (TCZ-SC) is administered every 2 weeks (q2w) or every week (qw), based on the patient's weight and clinical response.

Objectives: To compare the effects on disease activity at week 24, when the dosing schedule of TCZ-SC was escalated from q2w to qw, in patients who did not achieve LDA (DAS28-ESR > 3.2) at week 12 in COMP-ACT with patients who, despite not achieving LDA, continued TCZ-SC qw in SUMMACTA and q2w in BREVACTA.

Methods: US patients in COMP-ACT who weighed $<100 \mathrm{~kg}$ at baseline and who received TCZ-SC $162 \mathrm{mg}$ q2w + methotrexate escalated to qw if they did not achieve LDA at week 12. DAS28-ESR remission $(<2.6)$ and LDA $(\leq 3.2)$, CDAI remission $(\leq 2.8)$ and LDA $(\leq 10)$ and SDAI remission $(\leq 3.3)$ and LDA $(\leq$ 11 ) at week 24 were compared between patients who switched from q2w to qw and North American patients in SUMMACTA who initiated TCZ qw + csDMARDs and continued a qw dose (baseline body weight $<100 \mathrm{~kg}$ and DAS28 $>3.2$ at week 12). A secondary analysis compared COMP-ACT patients who escalated from $q 2 w$ to $q w$ with all SUMMACTA patients who continued a qw dose and all BREVACTA patients who initiated a TCZ-SC q2w dose + csDMARDs and continued a q2w dose (baseline body weight $<100 \mathrm{~kg}$ and DAS28 $>3.2$ at week 12). DAS28 was standardized to DAS28-ESR, and comparisons were calculated using a mixed model with repeated-measures logistic regression, including the following covariates: CDAI, SDAI and/or DAS28 at the reference visit (week 12), as well as study baseline values of CDAI, SDAI and/or DAS28, baseline age, sex, TNFi use prior to the study (yes or no) and weight category.

Results: A total of 328 US patients in COMP-ACT did not achieve LDA at week 12 and escalated from q2w to qw TCZ-SC. In SUMMACTA, 285 patients did not achieve LDA at week 12 and continued TCZ-SC qw, of whom 71 were from North America. Baseline demographic and clinical characteristics were comparable between patients in COMP-ACT and North American patients in SUMMACTA. A significantly higher proportion of patients in COMP-ACT achieved DAS28-ESR, CDAI and SDAI remission and LDA 12 weeks after TCZ dose escalation (week 24) than North American SUMMACTA patients (Table 1). Similar results were seen when the proportion of patients who achieved DAS28 remission and LDA was compared at week 24 between patients in COMP-ACT and patients from all geographic regions who did not escalate dosing in SUMMACTA and BREVACTA $(\mathrm{N}=196)$.

Conclusion: US patients with RA who did not achieve LDA and escalated from q2w to qw TCZ-SC at week 12 in COMP-ACT had better disease activity outcomes at week 24 than North American patients who did not achieve LDA and continued qw dosing in SUMMACTA. These results provide some evidence that escalation from $q 2 w$ to $q w$ has more effect than expected without dose change for patients who do not achieve LDA by week 12 .

Table 1. Comparison at Week 24 of Clinical Response After Week 12 Dose Escalation or Continuation Between Patients Who Did Not Achieve LDA at Week 12

\begin{tabular}{|c|c|c|c|c|}
\hline & $\begin{array}{c}\text { All } \\
\text { COMP-ACT } \\
(\mathrm{N}=328)\end{array}$ & $\begin{array}{c}\text { North American } \\
\text { SUMMACTA } \\
(n=71)\end{array}$ & $\begin{array}{l}\text { All SUMMACTA } \\
(\mathrm{N}=\mathbf{2 8 5})\end{array}$ & $\begin{array}{l}\text { All BREVACTA } \\
(\mathrm{N}=196)\end{array}$ \\
\hline $\begin{array}{l}\text { DAS28-ESR remission, } \\
\text { n (\%) }\end{array}$ & $66(20.1)$ & $7(9.9)$ & $44(15.4)$ & $36(18.4)$ \\
\hline Adjusted OR $(95 \% \mathrm{Cl})$ & Ref & $5.76(1.92,17.32)$ & $3.29(2.11,5.12)$ & $\begin{array}{c}2.35(1.44, \\
3.84)\end{array}$ \\
\hline$P$ value & Ref & 0.0018 & $<0.0001$ & 0.0006 \\
\hline DAS28-ESR LDA, n (\%) & $122(37.2)$ & $17(23.9)$ & $90(31.6)$ & $60(30.6)$ \\
\hline Adjusted OR $(95 \% \mathrm{Cl})$ & Ref & $3.36(1.61,7.00)$ & $2.81(1.97,4.01)$ & $\begin{array}{c}2.24(1.50, \\
3.33)\end{array}$ \\
\hline$P$ value & Ref & 0.0012 & $<0.0001$ & $<0.0001$ \\
\hline CDAI remission, $\mathrm{n}(\%)$ & $12(3.7)$ & $2(2.8)$ & $13(4.6)$ & $11(5.6)$ \\
\hline Adjusted OR (95\% Cl) & Ref & $4.50(1.32,15.32)$ & $2.93(1.37,6.27)$ & $\begin{array}{c}1.45(0.69 \\
3.05)\end{array}$ \\
\hline$P$ value & Ref & 0.0161 & 0.0056 & 0.3325 \\
\hline CDAI LDA, n (\%) & $80(24.4)$ & $11(15.5)$ & $81(28.4)$ & $66(33.7)$ \\
\hline Adjusted OR $(95 \% \mathrm{Cl})$ & Ref & $4.19(1.88,9.35)$ & $2.35(1.63,3.39)$ & $1.32(0.88,1.97)$ \\
\hline$P$ value & Ref & 0.0005 & $<0.0001$ & 0.1825 \\
\hline SDAI remission, n (\%) & $16(4.9)$ & $2(2.8)$ & $15(5.3)$ & $11(5.6)$ \\
\hline Adjusted OR $(95 \% \mathrm{Cl})$ & Ref & $5.23(1.44,19.01)$ & $3.23(1.54,6.76)$ & $\begin{array}{c}1.64(0.81 \\
3.30)\end{array}$ \\
\hline$P$ value & Ref & 0.0120 & 0.0019 & 0.1670 \\
\hline SDAI LDA, n (\%) & $89(27.1)$ & $11(15.5)$ & $91(31.9)$ & $72(36.7)$ \\
\hline Adjusted OR $(95 \% \mathrm{Cl})$ & Ref & $4.68(2.20,9.99)$ & $2.20(1.56,3.11)$ & $\begin{array}{c}1.47(0.99, \\
2.17)\end{array}$ \\
\hline$P$ value & Ref & $<0.0001$ & $<0.0001$ & 0.0540 \\
\hline
\end{tabular}

Acknowledgements: This study was funded by Genentech, Inc. Support for third-party writing assistance, furnished by Health Interactions, Inc., was provided by Genentech, Inc.

Disclosure of Interests: Nora Singer Grant/research support from: Genentech/Roche, Merck and Pfizer, Shalini Mohan Shareholder of: Genentech, Inc., Employee of: Genentech, Inc., Jian Han Shareholder of: Genentech, Inc. Employee of: Genentech, Inc., Michael Edwardes Employee of: Everest Clinica Research, Margaret Michalska Shareholder of: Genentech, Inc., Employee of: Genentech, Inc.

DOI: 10.1136/annrheumdis-2021-eular.795

\section{AB0204 THE PROPER STUDY: INTERIM ANALYSIS OF A PAN-EU REAL-WORLD STUDY OF SB5 BIOSIMILAR FOLLOWING TRANSITION FROM REFERENCE ADALIMUMAB IN PATIENTS WITH RHEUMATOID ARTHRITIS, AXIAL SPONDYLOARTHRITIS, OR PSORIATIC ARTHRITIS}

$\underline{\text { U. Müller-Ladner }}{ }^{1}$, K. Gaffney ${ }^{2}$, D. Jadon ${ }^{3}$, U. Freudensprung ${ }^{4}$, J. Addison ${ }^{5}$. ${ }^{1}$ Kerckhoff Klinik, Justus Liebig Universität Gießen, Abteilung für Rheumatologie und Klinische Immunologie, Bad Nauheim, Germany; ${ }^{2} \mathrm{NHS}$ Foundation Trust, Norfolk and Norwich University Hospital, Norwich, United Kingdom; ${ }^{3} \mathrm{NHS}$ Foundation Trust, Cambridge University Hospitals, Cambridge, United Kingdom; ${ }^{4}$ Biogen $\mathrm{GmbH}$, Medical Data Science and Analytics, Biosimilars, Baar, Switzerland; ${ }^{5}$ Biogen IDEC, Clinical Research, Biosimilars, Maidenhead, United Kingdom 